\title{
Controversies in Screening and Diagnostic Criteria for Gestational Diabetes in Early and Late Pregnancy
}

\author{
Evelyn A. Huhn ${ }^{1 *}$, Simona W. Rossi ${ }^{2}$, Irene Hoesli ${ }^{1}$ and Christian S. Göb/ ${ }^{3}$ \\ ${ }^{1}$ Department of Obstetrics and Gynaecology, University Hospital Basel, Basel, Switzerland, ${ }^{2}$ Department of Biomedicine, \\ University of Basel and University Hospital Basel, Basel, Switzerland, ${ }^{3}$ Division of Obstetrics and Feto-Maternal Medicine, \\ Department of Obstetrics and Gynaecology, Medical University of Vienna, Vienna, Austria
}

This review serves to evaluate the screening and diagnostic strategies for gestational diabetes and overt diabetes in pregnancy. We focus on the different early screening and diagnostic approaches in first trimester including fasting plasma glucose, random plasma glucose, oral glucose tolerance test, hemoglobin A1c, risk prediction models and biomarkers. Early screening for gestational diabetes is currently not recommended since the potential benefits and harms of early detection and subsequent treatment need to be further evaluated in randomized controlled trials.

Keywords: gestational diabetes (GDM), screening, diagnostic criteria, pregnancy, early biomarkers

\section{OPEN ACCESS}

Edited by:

Wei Bao,

University of lowa, United States

Reviewed by:

Julianne Toohey,

University of California, Irvine,

United States

Yeyi Zhu,

Kaiser Permanente Division of

Research, United States

*Correspondence:

Evelyn A. Huhn

evelyn.huhn@usb.ch

Specialty section:

This article was submitted to

Diabetes,

a section of the journal

Frontiers in Endocrinology

Received: 30 June 2018 Accepted: 05 November 2018 Published: 27 November 2018

Citation:

Huhn EA, Rossi SW, Hoesli I and Göbl CS (2018) Controversies in Screening and Diagnostic Criteria for Gestational Diabetes in Early and Late Pregnancy. Front. Endocrinol. 9:696. doi: 10.3389/fendo.2018.00696

\section{INTRODUCTION}

Gestational diabetes mellitus (GDM) is known to manifest in the second half of pregnancy in the setting of profound physiologic insulin resistance. Therefore, GDM is normally diagnosed after 24 weeks of gestation. The screening and diagnosis of GDM vary widely between medical specialties and among countries. Controversial areas surrounding screening for GDM include recommendations not to screen at all, a universal vs. a risk-based, selective approach, optimal timing of screening, the appropriate screening method [fasting plasma glucose (FPG), random plasma glucose (RPG), glucose challenge test (GCT)], or criteria for diagnosis (1 or 2 step, 75 vs. $100 \mathrm{~g}$ glucose load, whether 1 or 2 abnormal values are required for the diagnosis) and the appropriate cut-off values. Furthermore, there are debates concerning the relevance of treating additionally diagnosed, milder forms of GDM and about the cost effectiveness of different screening or diagnostic strategies. This article provides an update on screening and diagnostic strategies for GDM and overt diabetes. Furthermore, we will discuss the latest developments regarding early detection of GDM in the first trimester.

\section{THE LONG-LASTING WAY OF DEVELOPING SCREENING AND DIAGNOSTIC CRITERIA}

After almost six decades of research and tremendous effort to reach a consensus a globally and uniformly accepted guideline regarding how and when to screen and diagnose GDM is still not available. The original criteria were established based on the 3-h $100 \mathrm{~g}$ OGTT by O'Sullivan and Mahan in 1964 and predicted women who were most likely to develop type 2 diabetes mellitus (T2DM) later in life after pregnancy (1). But consecutive studies could show that even lesser degrees of hyperglycaemia were associated with an increased risk of adverse perinatal outcome, including large for gestational age fetuses, shoulder dystocia, neonatal hypoglycaemia, increased risk of cesarean section or hypertensive disorders (2-5). Subsequently, the Hyperglycaemia and Adverse Pregnancy Outcome (HAPO) study reported a linear continuous relationship between 
maternal hyperglycaemia and perinatal adverse outcome, making it difficult to define clear diagnostic thresholds (6). Based on these results, the International Association of Diabetes and Pregnancy Study Groups (IADPSG) developed a new guideline in 2010 recommending a universal one-step diagnostic test using the OGTT $75 \mathrm{~g}$ between 24 and 28 weeks of gestation with only one value to be considered as abnormal (7). Using the new criteria, the prevalence of GDM increased in the HAPO study to approximately $18 \%$, but varied widely among the different population demographics. For example, the prevalence in the HAPO study ranged between 9.3 and $25.5 \%$ dependent on the participating center (8). The new diagnostic thresholds have significant impact on costs and on infrastructure capacity. But many experts justify the criteria and the increase in workload in the background of the globally mounting burden of T2DM (9). The IADPSG thresholds were accepted by many health care organizations such as the WHO in 2013 and are now referred to as the 2013 WHO criteria (10). But the debate about screening and diagnostic criteria still goes on. The American Diabetes Association (ADA), which endorsed the IADPSG criteria in 2011, amended their guideline in 2014 and now considers both approaches (the one-step $75 \mathrm{~g}$ OGTT and the two-step screening: GCT followed by a $100 \mathrm{~g}$ OGTT if abnormal) acceptable for GDM diagnosis (11). The ADA states that there are insufficient data to demonstrate the superiority of one screening and diagnostic approach over the other, as-using the 2013 WHO criteriathe impact on costs and short and long term outcome of mother and her offspring have not been adequately evaluated. In their updated guideline from 2018, the American College of Obstetricians and Gynecologists (ACOG) recommends the twostep screening approach using the Carpenter and Coustan or the National Diabetes Data Group criteria and states however that "individual practices and institutions may choose to use the IADPSG recommendations" (12) The International Federation of Gynecology and Obstetrics (FIGO) acknowledged the problems with varying resource settings in different regions in their guideline from 2015 (13). The 2013 WHO criteria are generally recommended but the performance of OGTT vary depending on local circumstances. Diagnosis should be based on results from venous serum or plasma, but the use of plasma-calibrated handheld glucometers may be acceptable in locations where laboratory support is unavailable. While the 2013 WHO criteria are becoming more widely accepted, the main diabetes and obstetric societies still struggle to find the ideal algorithm. Large-scale randomized controlled trials studying the impact of intervention on women who meet different GDM criteria and evaluating the cost effectiveness of changes in short- and long-term outcomes might help solve these problems.

\section{SCREENING FOR OVERT DIABETES IN PREGNANCY AND RATIONALE FOR EARLY GDM SCREENING}

Many health organizations recommend to test for overt diabetes in women at high risk at the first prenatal visit $(7,11)$. Women with overt diabetes in pregnancy suffer from a higher rate of vascular dysfunction. They have a higher risk of congenital malformation and a significantly increased risk of adverse pregnancy outcome (14). These women benefit the most from early treatment. However, early testing will also lead to the identification of hyperglycaemia under the threshold for overt diabetes in pregnancy. Like screening and diagnosis of GDM in late pregnancy, there is also no consensus on the diagnostic criteria for "early" GDM. Many experts do not recommend screening for GDM in the first trimester at all, as no valid data exists about the benefits and harms of diagnosing and treating GDM in early gestation (15). The aim of early testing would be mainly to identify women at low or high risk for GDM. This risk stratification would diminish the need for universal screening and diagnosis from 24 weeks onwards and would reduce workload and costs. The second goal would be to identify women who already have GDM and to start treatment as early as possible to adequately ameliorate the adverse short and long-term effects of prolonged intrauterine exposure to hyperglycaemia. Maternal hyperglycaemia occurring even before diagnosis of GDM after 24 weeks of gestation seems to already increase the rate of fetal growth (16) and-if treatment starts after 26 weeks-infant adiposity $(17,18)$. Recent studies suggest a long term risk for the offspring for T2DM and cardiovascular disease. GDM seems to influence DNA methylation involved in energy metabolism and anti-inflammatory processes. This "metabolic programming" might be modified by later intervention during pregnancy, but this needs to be elucidated in future studies. After assessment of GDM in first trimester-theoretically by nowearly intervention would be of benefit for women who might be at highest risk for adverse pregnancy and long-term outcomes.

\section{METHODS FOR EARLY GDM SCREENING}

Many different methods have been evaluated for the screening of GDM in early pregnancy. There are direct glycaemic markers such as FPG, RPG, GCT, and/or OGTT, indirect methods like glycosylated hemoglobin $\mathrm{Alc}(\mathrm{HbA1c})$ or fructosamine and newer biochemical markers, many of which have been derived from proteomic or metabolomic analyses. We discuss the most promising approaches in detail below.

\section{Fasting and Random Plasma Glucose in Early Pregnancy}

Most health care organizations agree that screening for pre-conceptionally undiagnosed diabetes during pregnancy is recommendable, especially in high risk populations (19). Accordingly, the main advantage of FPG is its usefulness in diagnosing overt diabetes already at the first antenatal visit using standard diagnosis criteria [i.e., if FPG exceeds $125 \mathrm{mg} / \mathrm{dl}(6.9$ $\mathrm{mmol} / \mathrm{l})](7,13,20)$. Although the IADPSG consensus panel recommended in 2010 that GDM could be diagnosed by FPG concentrations between 92 and $125 \mathrm{mg} / \mathrm{dl}$ (5.1 and $6.9 \mathrm{mmol} / \mathrm{l})$ at any time during gestation (including the first trimester), as well, this approach was criticized due to lack of evidence (20). First, the IADPSG thresholds considered diagnostic for GDM were derived from the HAPO study, where FPG and OGTT glucose 
levels were assessed in the late second and early third trimester (6). Moreover, one study from Asia showed a continuous fall of FPG values during first trimester (21). Hence, the IADPSG cutoffs are not necessarily applicable at earlier gestational periods (9). Second, there are no randomized clinical trials available supporting any benefit of treating GDM diagnosed before 24 weeks of gestation (19). Due to these concerns, some authors suggested that the use of the IADPSG threshold for FPG is not justified in early pregnancy and IADPSG representatives issued a statement in 2016 to discontinue use of the FPG threshold (15). However, higher first trimester FPG levels might be regarded as an independent risk factor for later GDM development, comparable to pre-gestational BMI (22). Indeed, previous studies indicated an association between first trimester FPG and GDM manifestation between 24 and 28 weeks of gestation by using the IADPSG cut-offs, with concordance measures (area under the receiver operating characteristic curve, ROC-AUC) ranging between 0.614 (23) and 0.654 (21), respectively. Of note, one recent retrospective study suggested that RPG assessed between 12 and 16 weeks is able to predict GDM according to various diagnostic criteria with an ROC-AUC of 0.80 (24). This seems to be surprisingly high compared to the concordance measures observed for FPG. Although results are conflicting (previous studies reported a less optimistic ROC-AUC of 0.69 for RPG assessed between 24 and 28 weeks of gestation) and RPG might be affected by several pre-test conditions such as food intake, it has several advantages regarding time and cost effectiveness $(24,25)$. Thus, future research including prospective confirmatory studies are necessary.

\section{OGTT in Early Pregnancy}

An early OGTT (using an oral glucose load of $75 \mathrm{~g}$ glucose dissolved in $300 \mathrm{ml}$ water) before 24 weeks of gestation could be also used for diagnosing overt diabetes if the 2-h plasma glucose level exceeds $199 \mathrm{mg} / \mathrm{dl}(11.1 \mathrm{mmol} / \mathrm{l})$ according to FIGO and WHO guidelines $(10,13)$. Regarding diagnosis of GDM before 24 weeks of gestation the same concerns might be valid as discussed above for FPG. However, a recent study found that women meeting the IADPSG cut-offs already early in gestation showed impaired insulin sensitivity, which was partly explained by a higher degree of obesity in these patients (26). In accordance with these results, Lapolla et al. observed impaired insulin sensitivity in patients with early GDM diagnosis using the Carpenter-Coustan criteria (27).

\section{Glycosylated Hemoglobin A1c in Early Pregnancy}

HbA1c can be also used to detect overt diabetes at the first antenatal visit $[\geq 6.5 \%(48 \mathrm{mmol} / \mathrm{mol})]$ according to current guidelines. The test should be performed in a laboratory using a NGSP (National Glycohemoglobin Standardization Program) certified method standardized to the DCCT (Diabetes Control and Complication Trial) assay (20). Comparable to RPG, HbA1c has the advantage that it is inexpensive and does not require the fasting state. Fong and co-workers assessed its predictive performance for GDM progression in a retrospective cohort study which concluded that HbA1c levels between 5.7 and
$6.4 \%(39-46 \mathrm{mmol} / \mathrm{mol})$ could effectively identify patients at highest risk of developing GDM (28). A further study from New Zealand indicated that $\mathrm{HbAlc} \geq 5.9 \%(41 \mathrm{mmol} / \mathrm{mol})$ is highly predictive for pre-existing diabetes and adverse pregnancy outcomes (29). In addition, another study from Switzerland concluded that all pregnant women with first trimester HbAlc $\geq 6.0 \%$ (42 $\mathrm{mmol} / \mathrm{mol}$ ) developed GDM later in pregnancy, whereas those with $\mathrm{HbAlc}<4.5 \%$ (26 mmol/mol) did not (30). Conversely, Agarwal et al. found that the ROC-AUC of HbAlc assessed between 24 and 28 weeks was 0.54 and concluded that $\mathrm{HbA1c}$ remains a poor screening test for GDM using the WHO 1999 criteria (31). It might be of importance that HbAlc is subjected to pregnancy specific changes (32), requiring trimester specific reference values (33). Moreover, data from women after pregnancy with GDM indicated that HbAlc in the pre-diabetic range is a weak surrogate for the underlying pathophysiological components of impaired glucose metabolism, including impaired insulin action and $\beta$-cell dysfunction (34). Hence, HbA1c might be inferior to other tests for detecting subtle alterations in glucose metabolism.

\section{Other Biochemical Markers}

The current "gold standard" OGTT has a low reproducibility, is time consuming, unpleasant for some patients, dependent on ethnicity and the amount of glucose is given without consideration of maternal BMI (35). Therefore, the search for a simple, non-fasting point-of-care test or a risk model incorporating biomarkers (for a summary of risk models incorporating biomarkers \pm maternal factors see Table 1) seems to be a logical consequence. Many biochemical markers in the first trimester have been evaluated (Figure 1), but often only in small case-control observations without further prospective validation. Some biomarkers such as fasting insulin, inflammatory markers such as C-reactive protein (CRP) or tumor necrosis factor- $\alpha$ (TNF- $\alpha$ ) or soluble (pro)renin receptor failed to provide additional information about GDM risk beyond the risk assessment by clinical risk factors such as maternal BMI $(47,49,50)$.

The currently available marker, placenta growth factor (PlGF), is highly expressed by the placenta. Low PlGF levels in early pregnancy as a sign of poor placentation were observed in women with preeclampsia and/or intrauterine growth restriction (IUGR) and PlGF is now widely used for predicting preeclampsia at the time of the aneuploidy screening in 11-14 weeks of gestation (51). In a small case-control study, Eleftheriades et al. could show an increase of PlGF in early pregnancy in women with GDM compared to unaffected pregnant women (37). A risk prediction model with maternal factors alone could be improved from an AUC of 0.73 to 0.77 by the addition of PlGF but not pregnancy associated plasma proteinA (PAPP-A). On the other hand, a large prospective cohort study from the UK with over 31,000 recruited women showed only little advantage in incorporating PlGF and PAPP-A to a risk model which included maternal factors (AUC 0.84) (36). Conflicting results also exist for PAPP-A. Some studies report that PAPP-A levels are decreased in early pregnancy in women who subsequently developed GDM (52-55), others show no 
TABLE 1 | Summary of biomarkers tested in a multivariate model for later development of gestational diabetes.

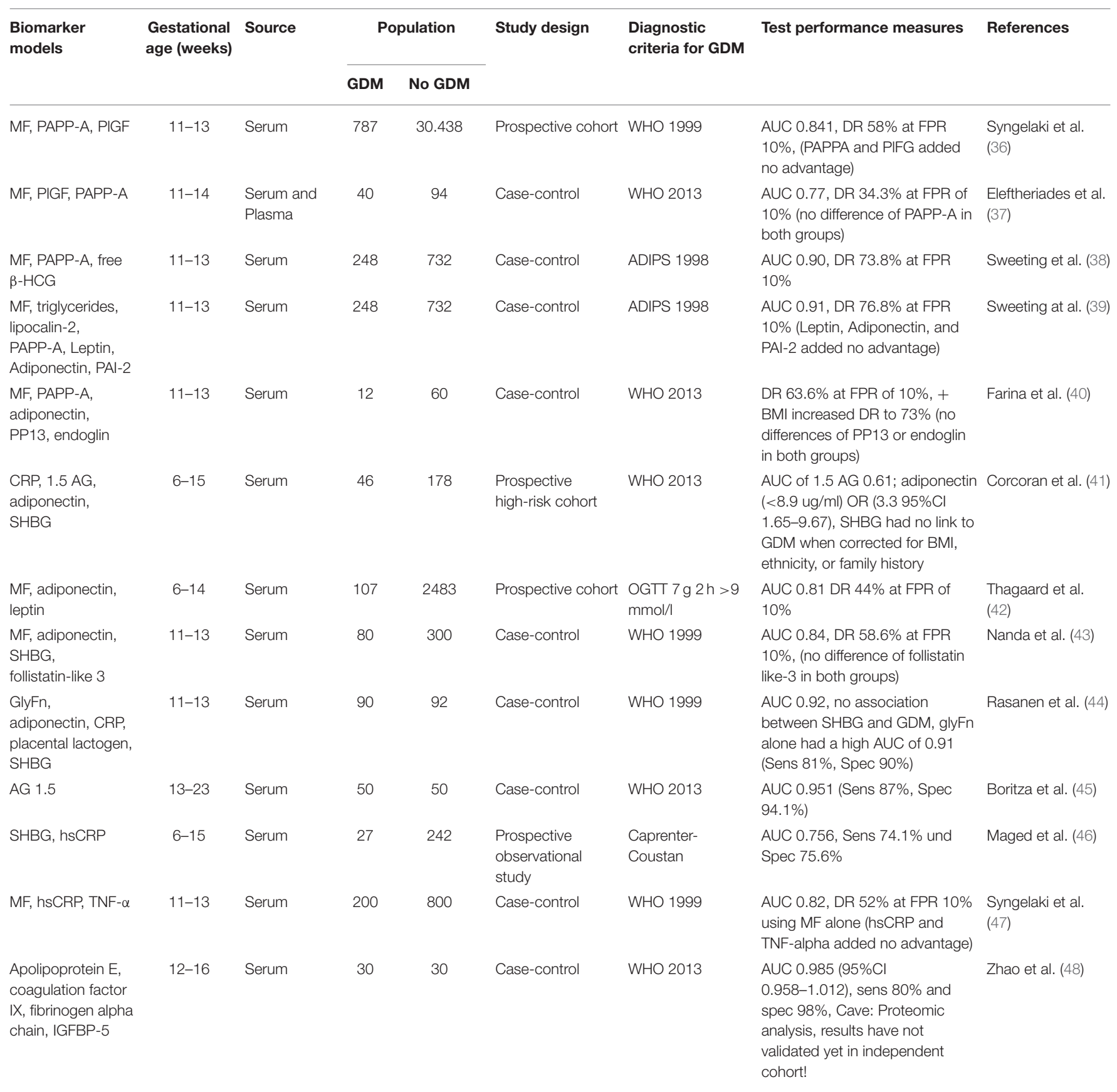

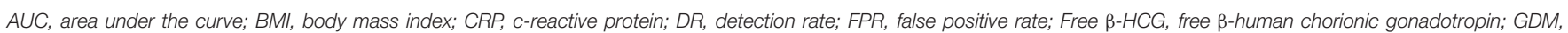

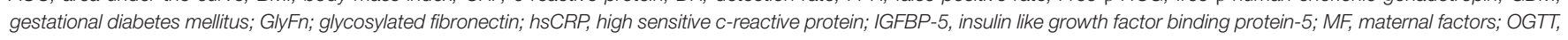

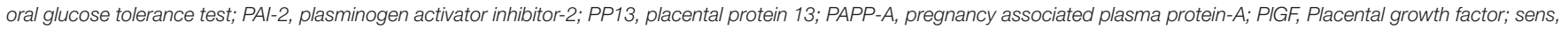
sensitivity; SHBG, sexual hormone binding globulin; spec, specificity; TNF- $\alpha$, tumor necrosis factor- $\alpha$; WHO, world health organization; 1.5 AG, 1.5 Anhydroglucitol.

differences in comparison to normal women $(56,57)$. Sweeting et al. reported a lower PAPP-A level especially in women of South Asian ethnicity and in multiparous women (38). The addition of aneuploidy markers increased the predictive value with an AUC of $0.88 \%$ by maternal factors alone to $0.90 \%$ with a detection rate (DR) of $73.8 \%$ at a false positive rate (FPR) of $10 \%$.
Adipocytokines such as adiponectin and leptin are hormones secreted by adipose tissue. Adiponectin plays an important role in glucose regulation and seems to be a good marker for whole body insulin sensitivity (58). A recent meta-analysis incorporating eight studies using early pregnancy adiponectin levels suggested moderate predictive ability of adiponectin in the prediction of GDM with an AUC of 0.79 , a sensitivity of $60.3 \%$ (95\% CI 


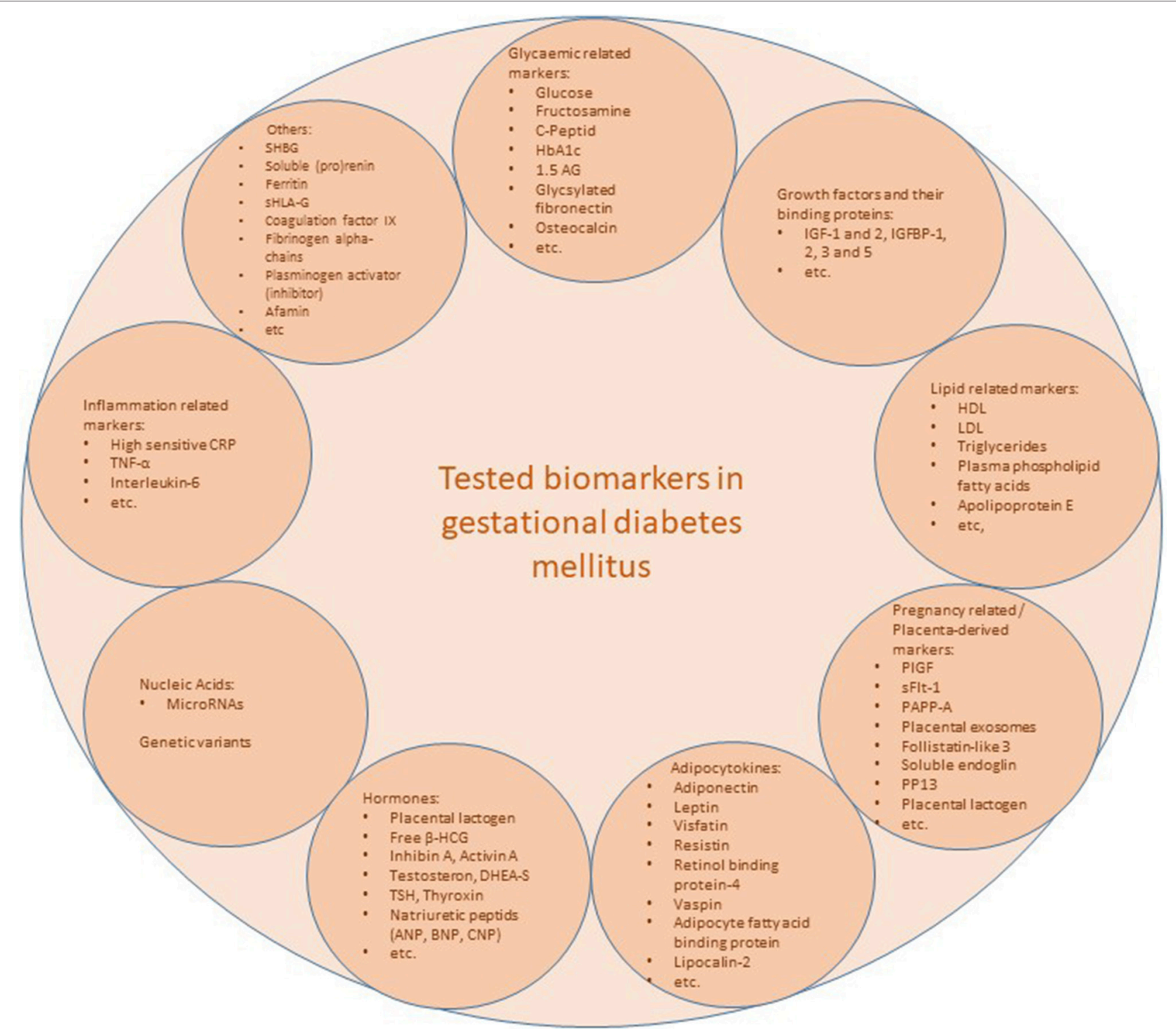

FIGURE 1 | Overview of tested biomarkers. CRP, c-reactive protein; Free $\beta$-HCG, free $\beta$-human chorionic gonadotropin; GlyFn; glycosylated fibronectin; HbA1c, hemoglobin A1c; HDL, high density lipoprotein; hsCRP, high sensitive c-reactive protein; IGF, insulin like growth factor; IGFBP, insulin like growth factor binding protein; LDL, low density lipoprotein; MF, maternal factors; PAl-2, plasminogen activator inhibitor-2; PP13, placental protein 13; PAPP-A, pregnancy associated plasma protein-A; PIGF, Placental growth factor; microRNAs, micro ribonucleic acids; sFlt-1, soluble Fms-like tyrosine kinase-1; SHBG, sexual hormone binding globulin; sHLA-G, soluble human leucocyte antigen-G; TNF- $\alpha$, tumor necrosis factor- $\alpha$; TSH, thyroid-stimulating hormone; 1.5 AG, 1.5 Anhydroglucitol.

$46,0 \%, 73.1 \%)$ and a specificity of $81.3 \%$ (95\% CI $71.6 \%, 88.3 \%)$ (59). Leptin regulates energy intake and expenditure and its levels correlate with the amount of visceral fat in first trimester (60). Qiu et al. found that each $10 \mathrm{ng} / \mathrm{ml}$ increase in leptin level was associated with a $20 \%$ higher risk of GDM (61), but others reported no alterations in leptin levels in women who subsequently developed GDM (62) or only an association in severely obese women (42). The latter study reported an AUC of 0.82 with a DR of $42 \%$ at a FPR of $10 \%$ in normal weight and moderately obese women when adiponectin and leptin were included in the maternal factor-based risk model. In a moderate sized case-control study (44), first trimester adiponectin and a newly introduced biomarker glycosylated fibronectin (GlyFn) were independently associated with later GDM development after adjustment for maternal clinical parameters (but not maternal BMI) with an AUC of 0.91 for GlyFn and an AUC of 0.63 for adiponectin. The glycated protein GlyFn still needs to be further validated in large prospective studies. Another marker of short-term glycaemic control is 1.5 Anhydroglucitol (1.5 AG). 1.5 AG is the 1-deoxy form of glucose and is a marker for short term (prior 24-72 h) glycaemic control and variances. Boritza et al. (45) could show that $1.5 \mathrm{AG}$ could discriminate women with 
GDM and normal women before 20 weeks of gestation in a small case-control study. 1.5 AG had a high predictive value with an AUC of 0.951 , a sensitivity of $87 \%$ and a specificity of $94.1 \%$ with a cut-off of $\leq 60.3 \mathrm{umol} / \mathrm{l}$.

Nonetheless, new biomarkers will need several years to evaluate and large-scale prospective observational studies to prove their clinical utility, as well as, to assess their cost effectiveness in comparison to later GDM screening and diagnosis are necessary. Additionally, it is unlikely that only one biomarker will have high enough sensitivity and specificity to assess early maternal hyperglycaemia. It is more likely that the combination of multiple parameters including baseline maternal characteristics such as BMI will achieve adequate predictive performances, as is the case with first trimester screening for aneuploidy or more recently for preeclampsia. Additionally, the fast-developing field of "omics," in particular proteomic and metabolomic analyses, will provide deeper insights into the pathophysiology of the different phenotypes of gestational diabetes. A specific protein or metabolite pattern will help to decipher biological processes in a more holistic way. These metabolic "fingerprints" of different body fluid sources could then be used for predictive purposes as has already been demonstrated in small case-control studies $(48,63)$.

\section{Risk Factor-Based Screening}

Clinical risk factors for GDM such as higher maternal age, obesity, GDM in a previous pregnancy, family history of diabetes, glycosuria, and ethnic background could be used in combination to identify women with increased risk of developing GDM. However, the proposed clinical risk indicators have shown limited diagnostic accuracy when used separately $(64,65)$. Therefore, some authors suggested that sensitivity and specificity for GDM screening with risk factors could be considerably improved by using clinical risk prediction models that include statistical combinations of several risk indicators (43, 65-70), which might be additionally combined with FPG $(71,72)$. Moreover, other biochemical markers might be included for improved prediction (73). However, the design of sufficient risk scores requires an adequate number of cases and healthy controls. As another limitation, the association of different risk factors (e.g., BMI) varies between different ethnic groups (74). Moreover, external validation in clinical practice is necessary (but often pending). A large number of risk estimation models for GDM can be found in the current literature, whereby most of them are based on different diagnostic criteria $(65-68,71)$. While they might be applicable even in early gestation to identify women at particularly high risk, their clinical significance has not been examined, or compared in independent populations.

\section{REFERENCES}

1. O'Sullivan JB, Mahan CM. Criteria for the oral glucose tolerance test in pregnancy. Diabetes. (1964) 13:278-85.

2. Yang $\mathrm{X}$, Hsu-Hage B, Zhang H, Zhang C, Zhang Y, Zhang C. Women with impaired glucose tolerance during pregnancy have significantly poor pregnancy outcomes. Diabetes Care (2002) 25:1619-24. doi: $10.2337 /$ diacare.25.9.1619
Furthermore, there is strong evidence from large epidemiological studies (75) that adherence to a healthy life-style (physical activity, healthy diet, non-smoker) prior to gestation is strongly associated with a lower risk for GDM. However, data on life-style factors is missing in published risk scoring algorithms, indicating the need for further research on this topic.

\section{MATERNAL CHARACTERISTICS OF EARLY VS. LATE GDM}

An overlap between the categorization of GDM and overt diabetes can be present if overt diabetes had not already been diagnosed before pregnancy. This in mind, pregnant women diagnosed with GDM in early pregnancy seem to be associated with worse pregnancy outcomes approximating those seen in overt diabetes (18). The data from Sweeting et al. suggests a heterogeneous "early" GDM phenotype with a continuous risk from overt diabetes in pregnancy to early GDM, with GDM diagnosed from 24 weeks of gestation onwards being the lowest risk condition. Additionally, maternal adiposity and a more insulin-resistant phenotype might also play a role in the heterogeneity of "early" GDM (26).

\section{CONCLUSION AND RECOMMENDATIONS}

GDM is currently diagnosed during the second or third trimester, when unfavorable metabolic dysfunctions might have already affected the mother and the fetus. The combination of maternal risk factors and the insulin resistance preceding biomarkers might improve early detection of a high risk GDM cohort. Future studies should evaluate whether early GDM screening and diagnosis can be improved with the addition of novel biomarkers implicated in the pathophysiology of GDM, whether earlier detection and intervention strategies can improve short and long term adverse outcome and whether the combined biomarker and maternal factor screening models are costeffective.

\section{AUTHOR CONTRIBUTIONS}

EH and CG drafted manuscript. SR and IH made substantial contribution to the content.

\section{ACKNOWLEDGMENTS}

We would like to thank Dr. Dorothy Huang for English proofreading.
3. Vambergue A, Nuttens MC, Verier-Mine O, Dognin C, Cappoen JP, Fontaine P. Is mild gestational hyperglycaemia associated with maternal and neonatal complications? The diagest study. Diabetes Med. (2000) 17:203-8. doi: 10.1046/j.1464-5491.2000. 00237.x

4. Langer O, Brustman L, Anyaegbunam A, Mazze R. The significance of one abnormal glucose tolerance test value on adverse outcome in pregnancy. Am J Obstet Gynecol. (1987) 157:758-63. 
5. Sermer M, Naylor CD, Gare DJ, Kenshole AB, Ritchie JW, Farine D, et al. Impact of increasing carbohydrate intolerance on maternal-fetal outcomes in 3637 women without gestational diabetes. The Toronto Tri-Hospital Gestational Diabetes Project. Am J Obstet Gynecol. (1995) 173:146-56.

6. HAPO Study Cooperative Research Group, Metzger BE, Lowe LP, Dyer AR, Trimble ER, Chaovarindr U, et al. Hyperglycemia and adverse pregnancy outcomes. N Engl J Med. (2008) 358:1991-2002. doi: 10.1056/NEJMoa0707943

7. Metzger BE, Gabbe SG, Persson B, Lowe LP, Dyer AR, Oats JJN, et al. International association of diabetes and pregnancy study groups recommendations on the diagnosis and classification of hyperglycemia in pregnancy. Diabetes Care (2010) 33:676-82. doi: 10.2337/dc09-1848

8. Sacks DA, Hadden DR, Maresh M, Deerochanawong C, Dyer AR, Metzger BE, et al. Frequency of gestational diabetes mellitus at collaborating centers based on IADPSG consensus panel-recommended criteria: the Hyperglycemia and Adverse Pregnancy Outcome (HAPO) study. Diabetes Care (2012) 35:526-28. doi: $10.2337 / \mathrm{dc} 11-1641$

9. Sacks DB, Coustan DR, Cundy T, Donovan L, Hod M. Gestational diabetes mellitus: why the controversy? Clin Chem. (2018) 64:431-8. doi: 10.1373/clinchem.2016.266577

10. World Health Organization. Diagnostic Criteria and Classification of Hyperglycaemia First Detected in Pregnancy: A World Health Organization Guideline (2013). Available online at: http://apps.who.int/iris/bitstream/ 10665/85975/1/WHO_NMH_MND_13.2_eng.pdf

11. American Diabetes Association. Standards of medical care in diabetes-2014. Diabetes Care (2014) 37(Suppl. 1):S14-80. doi: 10.2337/dc14-S014

12. Committee on Practice Bulletins-Obstetrics. ACOG Practice Bulletin No. 190: gestational diabetes mellitus. Obstet Gynecol. (2018) 131:e49-64. doi: 10.1097/AOG.0000000000002501

13. Hod M, Kapur A, Sacks DA, Hadar E, Agarwal M, Di Renzo GC, et al. The International Federation of Gynecology and Obstetrics (FIGO) initiative on gestational diabetes mellitus: a pragmatic guide for diagnosis, management, and care. Int J Gynaecol Obstet. (2015) 131(Suppl.):S173-211. doi: 10.1016/S0020-7292(15)30033-3

14. Abell SK, Nankervis A, Khan KS, Teede HJ. Type 1 and Type 2 diabetes preconception and in pregnancy: health impacts, influence of obesity and lifestyle, and principles of management. Semin Reprod Med. (2016) 34:110-20. doi: 10.1055/s-0035-1571196

15. McIntyre HD, Sacks DA, Barbour LA, Feig DS, Catalano PM, Damm P, et al. Issues with the diagnosis and classification of hyperglycemia in early pregnancy. Diabetes Care (2016) 39:53-4. doi: 10.2337/dc15-1887

16. Sovio U, Murphy HR, Smith GCS. Accelerated fetal growth prior to diagnosis of gestational diabetes mellitus: a prospective cohort study of nulliparous women. Diabetes Care (2016) 39:982-7. doi: 10.2337/dc16-0160

17. Logan KM, Emsley RJ, Jeffries S, Andrzejewska I, Hyde MJ, Gale C, et al. Development of early adiposity in infants of mothers with gestational diabetes mellitus. Diabetes Care (2016) 39:1045-51. doi: 10.2337/dc16-0030

18. Sweeting AN, Ross GP, Hyett J, Wong J. Gestational diabetes in the first trimester: is early testing justified? Lancet Diabetes Endocrinol. (2017) 5:571-3. doi: 10.1016/S2213-8587(17)30066-9

19. Egan AM, Hod M, Mahmood T, Dunne FP. Perspectives on diagnostic strategies for hyperglycaemia in pregnancy - dealing with the barriers and challenges: Europe. Diabetes Res Clin Pract. (2018). doi: 10.1016/j.diabres.2018.06.001. [Epub ahead of print].

20. Association Diabetes Association. 2. Classification and diagnosis of diabetes: standards of medical care in diabetes-2018. Diabetes Care (2018) 41(Suppl. 1):S13-27. doi: 10.2337/dc18-S002

21. Zhu WW, Yang HX, Wei YM, Yan J, Wang ZL, Li XL, et al. Evaluation of the value of fasting plasma glucose in the first prenatal visit to diagnose gestational diabetes mellitus in China. Diabetes Care (2013) 36:586-90. doi: $10.2337 / \mathrm{dc} 12-1157$

22. Riskin-Mashiah S, Damti A, Younes G, Auslender R. First trimester fasting hyperglycemia as a predictor for the development of gestational diabetes mellitus. Eur J Obstet Gynecol Reprod Biol. (2010) 152:163-7. doi: 10.1016/j.ejogrb.2010.05.036

23. Corrado F, D'Anna R, Cannata ML, Interdonato ML, Pintaudi B, Di Benedetto A. Correspondence between first-trimester fasting glycaemia, and oral glucose tolerance test in gestational diabetes diagnosis. Diabetes Metab. (2012) 38:458-61. doi: 10.1016/j.diabet.2012.03.006
24. Meek CL, Murphy HR, Simmons D. Random plasma glucose in early pregnancy is a better predictor of gestational diabetes diagnosis than maternal obesity. Diabetologia (2016) 59:445-52. doi: 10.1007/s00125-015-3811-5

25. van Leeuwen M, Zweers EJ, Opmeer BC, van Ballegooie E, ter Brugge HG, de Valk HW, et al. Comparison of accuracy measures of two screening tests for gestational diabetes mellitus. Diabetes Care (2007) 30:2779-84. doi: $10.2337 / \mathrm{dc} 07-0571$

26. Bozkurt L, Göbl CS, Pfligl L, Leitner K, Bancher-Todesca D, Luger A, et al. Pathophysiological characteristics and effects of obesity in women with early and late manifestation of gestational diabetes diagnosed by the International Association of Diabetes and Pregnancy Study Groups criteria. J Clin Endocrinol Metab. (2015) 100:1113-20. doi: 10.1210/jc.2014-4055

27. Lapolla A, Marangon M, Dalfrà MG, Segato G, De Luca M, Fedele D, et al. Pregnancy outcome in morbidly obese women before and after laparoscopic gastric banding. Obes Surg. (2010) 20:1251-7. doi: 10.1007/s11695-010-0199-7

28. Fong A, Serra AE, Gabby L, Wing DA, Berkowitz KM. Use of hemoglobin Alc as an early predictor of gestational diabetes mellitus. Am J Obstet Gynecol. (2014) 211:641.e1-7. doi: 10.1016/j.ajog.2014.06.016

29. Hughes RCE, Moore MP, Gullam JE, Mohamed K, Rowan J. An early pregnancy $\mathrm{HbAlc} \geq 5.9 \%(41 \mathrm{mmol} / \mathrm{mol})$ is optimal for detecting diabetes and identifies women at increased risk of adverse pregnancy outcomes. Diabetes Care (2014) 37:2953-9. doi: 10.2337/dc14-1312

30. Amylidi S, Mosimann B, Stettler C, Fiedler GM, Surbek D, Raio L. Firsttrimester glycosylated hemoglobin in women at high risk for gestational diabetes. Acta Obstet Gynecol Scand. (2016) 95:93-7. doi: 10.1111/aogs.12784

31. Agarwal MM, Dhatt GS, Punnose J, Koster G. Gestational diabetes: a reappraisal of HBAlc as a screening test. Acta Obstet Gynecol Scand. (2005) 84:1159-63. doi: 10.1111/j.0001-6349.2005.00650.x

32. Hughes RCE, Rowan J, Florkowski CM. Is there a role for HbAlc in pregnancy? Curr Diab Rep. (2016) 16:5. doi: 10.1007/s11892-015-0698-y

33. O'Connor C, O'Shea PM, Owens LA, Carmody L, Avalos G, Nestor $\mathrm{L}$, et al. Trimester-specific reference intervals for haemoglobin Alc (HbA1c) in pregnancy. Clin Chem Lab Med. (2011) 50:905-9. doi: 10.1515/CCLM.2011.397

34. Göbl CS, Bozkurt L, Yarragudi R, Tura A, Pacini G, Kautzky-Willer A. Is early postpartum $\mathrm{HbAlc}$ an appropriate risk predictor after pregnancy with gestational diabetes mellitus? Acta Diabetol. (2014) 51:715-22. doi: 10.1007/s00592-014-0574-2

35. Bonongwe P, Lindow SW, Coetzee EJ. Reproducibility of a $75 \mathrm{G}$ oral glucose tolerance test in pregnant women. J Perinat Med. (2015) 43:333-8. doi: 10.1515/jpm-2014-0208

36. Syngelaki A, Kotecha R, Pastides A, Wright A, Nicolaides KH. First-trimester biochemical markers of placentation in screening for gestational diabetes mellitus. Metabolism (2015) 64:1485-9. doi: 10.1016/j.metabol.2015.07.015

37. Eleftheriades M, Papastefanou I, Lambrinoudaki I, Kappou D, Lavranos D, Akalestos A, et al. Elevated placental growth factor concentrations at 11-14 weeks of gestation to predict gestational diabetes mellitus. Metabolism (2014) 63:1419-25. doi: 10.1016/j.metabol.2014.07.016

38. Sweeting AN, Wong J, Appelblom H, Ross GP, Kouru H, Williams PF., et al. A first trimester prediction model for gestational diabetes utilizing aneuploidy and pre-eclampsia screening markers. J Matern Neonatal Med. (2018) 31:2122-30. doi: 10.1080/14767058.2017.1336759

39. Sweeting AN, Wong J, Appelblom H, Ross GP, Kouru H, Williams PF, et al. A novel early pregnancy risk prediction model for gestational diabetes mellitus. Fetal Diagn Ther. (2018). doi: 10.1159/000486853. [Epub ahead of print].

40. Farina A, Eklund E, Bernabini D, Paladino M, Righetti F, Monti G, et al. A first-trimester biomarker panel for predicting the development of gestational diabetes. Reprod Sci. (2017) 24:954-9. doi: 10.1177/1933719116675057

41. Corcoran SM, Achamallah N, Loughlin JO, Stafford P, Dicker P, Malone FD, et al. First trimester serum biomarkers to predict gestational diabetes in a high-risk cohort: striving for clinically useful thresholds. Eur J Obstet Gynecol Reprod Biol. (2018) 222:7-12. doi: 10.1016/j.ejogrb.2017.12.051

42. Thagaard IN, Krebs L, Holm J-C, Lange T, Larsen T, Christiansen M. Adiponectin and leptin as first trimester markers for gestational diabetes mellitus: a cohort study. Clin Chem Lab Med. (2017) 55:1805-12. doi: $10.1515 / \mathrm{cclm}-2017-0427$

43. Nanda S, Savvidou M, Syngelaki A, Akolekar R, Nicolaides KH. Prediction of gestational diabetes mellitus by maternal factors and biomarkers at 11 to 13 weeks. Prenat Diagn. (2011) 31:135-41. doi: 10.1002/pd.2636 
44. Rasanen JP, Snyder CK, Rao PV, Mihalache R, Heinonen S, Gravett $\mathrm{MG}$, et al. Glycosylated fibronectin as a first-trimester biomarker for prediction of gestational diabetes. Obstet Gynecol. (2013) 122:586-94. doi: 10.1097/AOG.0b013e3182a0c88b

45. Boritza KC, dos Santos-Weiss IC, da Silva Couto Alves A, Réa RR, Pedrosa FO, de Souza EM, et al. 1,5 Anhydroglucitol serum concentration as a biomarker for screening gestational diabetes in early pregnancy. Clin Chem Lab Med. (2014) 52:e179-81. doi: 10.1515/cclm-2013-1042

46. Maged AM, Moety GAF, Mostafa WA, Hamed DA. Comparative study between different biomarkers for early prediction of gestational diabetes mellitus. J Matern Fetal Neonatal Med. (2014) 27:1108-12. doi: 10.3109/14767058.2013.850489

47. Syngelaki A, Visser GHA, Krithinakis K, Wright A, Nicolaides KH. First trimester screening for gestational diabetes mellitus by maternal factors and markers of inflammation. Metabolism (2016) 65:131-7. doi: 10.1016/j.metabol.2015.10.029

48. Zhao D, Shen L, Wei Y, Xie J, Chen S, Liang Y, et al. Identification of candidate biomarkers for the prediction of gestational diabetes mellitus in the early stages of pregnancy using iTRAQ quantitative proteomics. Proteomics Clin Appl. (2017) 11:1600152. doi: 10.1002/prca.201600152

49. Wolf M, Sandler L, Hsu K, Vossen-Smirnakis K, Ecker JL, Thadhani R. Firsttrimester C-reactive protein and subsequent gestational diabetes. Diabetes Care (2003) 26:819-24. doi: 10.2337/diacare.26.3.819

50. Watanabe N, Morimoto S, Fujiwara T, Suzuki T, Taniguchi K, Mori F, et al. Prediction of gestational diabetes mellitus by soluble (Pro)Renin receptor during the first trimester. J Clin Endocrinol Metab. (2013) 98:2528-35. doi: 10.1210/jc.2012-4139

51. O'Gorman N, Wright D, Syngelaki A, Akolekar R, Wright A, Poon LC, et al. Competing risks model in screening for preeclampsia by maternal factors and biomarkers at 11-13 weeks gestation. Am J Obstet Gynecol. (2016) 214:103.e1-12. doi: 10.1016/j.ajog.2015.08.034

52. Lovati E, Beneventi F, Simonetta M, Laneri M, Quarleri L, Scudeller L, et al. Gestational diabetes mellitus: including serum pregnancy-associated plasma protein-A testing in the clinical management of primiparous women? A case-control study. Diabetes Res Clin Pract. (2013) 100:340-7. doi: 10.1016/j.diabres.2013.04.002

53. Beneventi F, Simonetta M, Lovati E, Albonico G, Tinelli C, Locatelli E, et al. First trimester pregnancy-associated plasma protein-A in pregnancies complicated by subsequent gestational diabetes. Prenat Diagn. (2011) 31:523-8. doi: 10.1002/pd.2733

54. Tul N, Pusenjak S, Osredkar J, Spencer K, Novak-Antolic Z. Predicting complications of pregnancy with first-trimester maternal serum freebetahCG, PAPP-A and inhibin-A. Prenat Diagn. (2003) 23:990-6. doi: $10.1002 / \mathrm{pd} .735$

55. Spencer K, Cowans NJ. The association between gestational diabetes mellitus and first trimester aneuploidy screening markers. Ann Clin Biochem. (2013) 50:603-10. doi: 10.1177/0004563213480493

56. Husslein H, Lausegger F, Leipold H, Worda C. Association between pregnancy-associated plasma protein-A and gestational diabetes requiring insulin treatment at 11-14 weeks of gestation. J Matern Neonatal Med. (2012) 25:2230-3. doi: 10.3109/14767058.2012.684170

57. Savvidou M, Syngelaki A, Muhaisen M, Emelyanenko E, Nicolaides K. First trimester maternal serum free $\beta$-human chorionic gonadotropin and pregnancy-associated plasma protein $\mathrm{A}$ in pregnancies complicated by diabetes mellitus. BJOG An Int J Obstet Gynaecol. (2012) 119:410-6. doi: 10.1111/j.1471-0528.2011.03253.x

58. Yadav A, Kataria MA, Saini V, Yadav A. Role of leptin and adiponectin in insulin resistance. Clin Chim Acta. (2013) 417:80-4. doi: 10.1016/j.cca.2012.12.007

59. Iliodromiti S, Sassarini J, Kelsey TW, Lindsay RS, Sattar N, Nelson SM. Accuracy of circulating adiponectin for predicting gestational diabetes: a systematic review and meta-analysis. Diabetologia (2016) 59:692-9. doi: 10.1007/s00125-015-3855-6

60. Fattah C, Barry S, O'connor N, Farah N, Stuart B, Turner MJ. Maternal leptin and body composition in the first trimester of pregnancy. Gynecol Endocrinol. (2011) 27:263-6. doi: 10.3109/09513590.2010. 491167

61. Qiu C, Williams MA, Vadachkoria S, Frederick IO, Luthy DA. Increased maternal plasma leptin in early pregnancy and risk of gestational diabetes mellitus. Obstet Gynecol. (2004) 103:519-25. doi: 10.1097/01.AOG.0000113621.53602.7a

62. Maple-Brown L, Ye C, Hanley AJ, Connelly PW, Sermer M, Zinman B, et al. Maternal pregravid weight is the primary determinant of serum leptin and its metabolic associations in pregnancy, irrespective of gestational glucose tolerance status. J Clin Endocrinol Metab. (2012) 97:4148-55. doi: $10.1210 /$ jc.2012-2290

63. Guo Y, Han Z, Guo L, Liu Y, Li G, Li H, et al. Identification of urinary biomarkers for the prediction of gestational diabetes mellitus in early second trimester of young gravidae based on ITRAQ quantitative proteomics. Endocr J. (2018) 65:727-35. doi: 10.1507/endocrj.EJ17-0471

64. Griffin ME, Coffey $\mathrm{M}$, Johnson $\mathrm{H}$, et al. Universal vs. risk factorbased screening for gestational diabetes mellitus: detection rates, gestation at diagnosis and outcome. Diabet Med. (2000) 17:26-32. doi: 10.1046/j.1464-5491.2000.00214.x

65. van Leeuwen M, Opmeer BC, Zweers EJ, van Ballegooie E, ter Brugge HG, de Valk HW, et al. Estimating the risk of gestational diabetes mellitus: a clinical prediction model based on patient characteristics and medical history. BJOG (2010) 117:69-75. doi: 10.1111/j.1471-0528.2009.02425.x

66. Naylor CD, Sermer M, Chen E, Farine D. Selective screening for gestational diabetes mellitus. Toronto Trihospital Gestational Diabetes Project Investigators. N Engl J Med. (1997) 337:1591-6. doi: 10.1056/NEJM199711273372204

67. Phaloprakarn C, Tangjitgamol S, Manusirivithaya S. A risk score for selective screening for gestational diabetes mellitus. Eur J Obstet Gynecol Reprod Biol. (2009) 145:71-5. doi: 10.1016/j.ejogrb.2009.04.016

68. Caliskan E, Kayikcioglu F, Oztürk N, Koc S, Haberal A. A population-based risk factor scoring will decrease unnecessary testing for the diagnosis of gestational diabetes mellitus. Acta Obstet Gynecol Scand. (2004) 83:524-30. doi: 10.1111/j.0001-6349.2004.00389.x

69. Teede HJ, Harrison CL, Teh WT, Paul E, Allan CA. Gestational diabetes: development of an early risk prediction tool to facilitate opportunities for prevention. Aust N Z J Obstet Gynaecol. (2011) 51:499-504. doi: 10.1111/j.1479-828X.2011.01356.x

70. Syngelaki A, Pastides A, Kotecha R, Wright A, Akolekar R, Nicolaides KH. First-trimester screening for gestational diabetes mellitus based on maternal characteristics and history. Fetal Diagn Ther. (2015) 38:14-21. doi: $10.1159 / 000369970$

71. Göbl CS, Bozkurt L, Rivic P, Schernthaner G, Weitgasser R, Pacini G, et al. A two-step screening algorithm including fasting plasma glucose measurement and a risk estimation model is an accurate strategy for detecting gestational diabetes mellitus. Diabetologia (2012) 55:3173-81. doi: 10.1007/s00125-012-2726-7

72. Savona-Ventura C, Vassallo J, Marre M, Karamanos BG. A composite risk assessment model to screen for gestational diabetes mellitus among Mediterranean women. Int J Gynaecol Obstet. (2013) 120:240-4. doi: 10.1016/j.ijgo.2012.10.016

73. Savvidou M, Nelson SM, Makgoba M, Messow C-M, Sattar N, Nicolaides K. First-trimester prediction of gestational diabetes mellitus: examining the potential of combining maternal characteristics and laboratory measures. Diabetes (2010) 59:3017-22. doi: 10.2337/db10-0688

74. Shah A, Stotland NE, Cheng YW, Ramos GA, Caughey AB. The association between body mass index and gestational diabetes mellitus varies by race/ethnicity. Am J Perinatol. (2011) 28:515-20. doi: 10.1055/s-0031-1272968

75. Zhang C, Tobias DK, Chavarro JE, Bao W, Wang D, Ley SH, et al. Adherence to healthy lifestyle and risk of gestational diabetes mellitus: prospective cohort study. BMJ (2014) 349:g5450. doi: 10.1136/bmj.g5450

Conflict of Interest Statement: The authors declare that the research was conducted in the absence of any commercial or financial relationships that could be construed as a potential conflict of interest.

Copyright (c) 2018 Huhn, Rossi, Hoesli and Göbl. This is an open-access article distributed under the terms of the Creative Commons Attribution License (CC BY). The use, distribution or reproduction in other forums is permitted, provided the original author(s) and the copyright owner(s) are credited and that the original publication in this journal is cited, in accordance with accepted academic practice. No use, distribution or reproduction is permitted which does not comply with these terms. 